\title{
Cytotoxicity and anti-leishmanial activity of the Red Sea soft coral Sarcophyton spongiosum
}

\author{
Sabry A. H. Zidan ${ }^{1,2}$, Mohamed A. A. Orabi ${ }^{1}$, Reda. A. Abdelhamid ${ }^{1}$, Abdallah Alian ${ }^{3}$, Katsuyoshi Matsunami ${ }^{2}$, \\ Mostafa A. Fouad ${ }^{4}$ \\ ${ }^{1}$ Department of Pharmacognosy, Faculty of Pharmacy, Al-Azhar University, Assiut-Branch, Assiut 71524, Egypt \\ ${ }^{2}$ Department of Pharmacognosy, Graduate School of Biomedical and Health Sciences, Hiroshima University, 1-2-3 Kasumi, Minami-Ku, \\ Hiroshima 734-8553, Japan \\ ${ }^{3}$ Department of Zoology, Faculty of Science, Al-Azhar University, Assiut-Branch, Assiut, 71524, Egypt \\ ${ }^{4}$ Department of Pharmacognosy, Faculty of Pharmacy, Minia University, Minia 61519, Egypt
}

Received: February 17, 2021; revised: March 13, 2021; accepted: March 17, 2021

\begin{abstract}
The aim of the present study is the evaluation of the in-vitro cytotoxicity and antileishmanial activities of a methanolic extract and its different fractions of the soft coral Sarcophyton spongiosum collected from the Egyptian Red Sea against three cancer cell lines, A549, HepG2, and MCF-7, and a protozoan, Leishmania major, by the MTT assay protocol. The dichloromethane fraction exhibited significant anti-L. major $\left(\mathrm{IC}_{50} 28.1 \pm 1.2 \mu \mathrm{g} / \mathrm{mL}\right)$ and cytotoxic activities against $\mathrm{MCF}-7$ cell line $\mathrm{IC}_{50}(31.5 \pm 1.1$ $\mu \mathrm{g} / \mathrm{mL})$. The ethyl acetate fraction showed promising cytotoxicity against A549 and HepG2 cell lines (IC $5013.4 \pm 1.2$ and $11.6 \pm$ $1.9 \mu \mathrm{g} / \mathrm{mL}$, respectively). A preliminary chemical screening of the total methanolic extract indicated of the presence of sterols and diterpenes.
\end{abstract}

\section{Key words}

Soft corals; Sarcophyton spongiosum; cytotoxicity; anti-Leishmania; MTT assay.

\section{Introduction}

The marine natural products could be considered as an extraordinary resource for the discovery of new drugs due to its unique chemical and biological diversity [1]. The Red sea environment has several distinctive features that provided the biota with favorable conditions greater than anywhere else [1], which made the Red sea rich source of biodiversity from which a series of potential drugs have been discovered [1].

Of all the identified soft coral species so far, around $40 \%$ of them inhabit the Red Sea [1]. The marine soft corals are sessile colonial simple invertebrate that represent an important component of the coral reefs' ecosystem [2]. Soft corals lack a physical protection, but they rely on the toxic and antifeeding properties of their secondary metabolites to deter predators and compete for a space [3].

The Sarcophyton soft corals are abundant in the Red Sea [4, 5]. The Sarcophyton species extracts, and isolated secondary metabolites have been reported to exhibit anti-inflammatory, antibacterial, antiviral, neuroprotective and cytotoxic activities $[4,5]$.

Cancer is one of the major causes of mortality and morbidity in most developed countries and to an increasing extent in developing countries [6,7].

In Egypt, Liver and breast cancers have the most incidence rates among all types of cancers (23.8 and $14.4 \%$ respectively) [8]. The progressive increase in number of incident cases in Egypt is expected to be 331,169 by 2050 [6]. In the light of these rates of morbidity and mortality, the impulse to find and develop alternative or synergistic anti-cancer agents became priority among researchers.

On the other hand, cutaneous leishmaniasis, a disease caused by the protozoan parasite $L$. major, is the most common form of leishmaniasis affecting humans especially among countries of the Middle East and Asia [9, 10]. The protozoan L. major transmits from an infected person to a new one by a female sand-fly which belongs to the genus Phlebotomus [11]. Around 1.0-1.5 million new cases each year are infected by $L$. major worldwide [10]. There is no available vaccine for leishmaniasis yet [12]. Also, the toxic side effects, high cost, lack of selectivity, and the potential emergence of parasitic resistance of currently available drugs (such as pentavalent antimonials, miltefosine, and amphotericin B) made the searching for new effective and safe therapeutic approaches urgently required [12]. Our previous attempt to discover a new source for anticancer and/or antileishmanial drugs from natural source revealed that the Sarcophyton acutum could be considered as a promising source for this purpose [13]. So, the activity of other Sarcophyton species is expected and deserve searching. In this regard, the activities of the methanolic extract of the soft coral Sarcophyton spongiosum (Figure 1) and its $n$-hexane, dichloromethane (DCM), ethyl acetate (EtOAc), and methanol $(\mathrm{MeOH})$ fractions against L. major and three cancer cell lines, the breast cancer Michigan Cancer Foundation-7 (MCF-7), lung adenocarcinoma (A549), and hepatocellular carcinoma (HepG2) were examined and compared with miltefosine as a standard antileishmanial and etoposide as a standard cytotoxic drugs. 


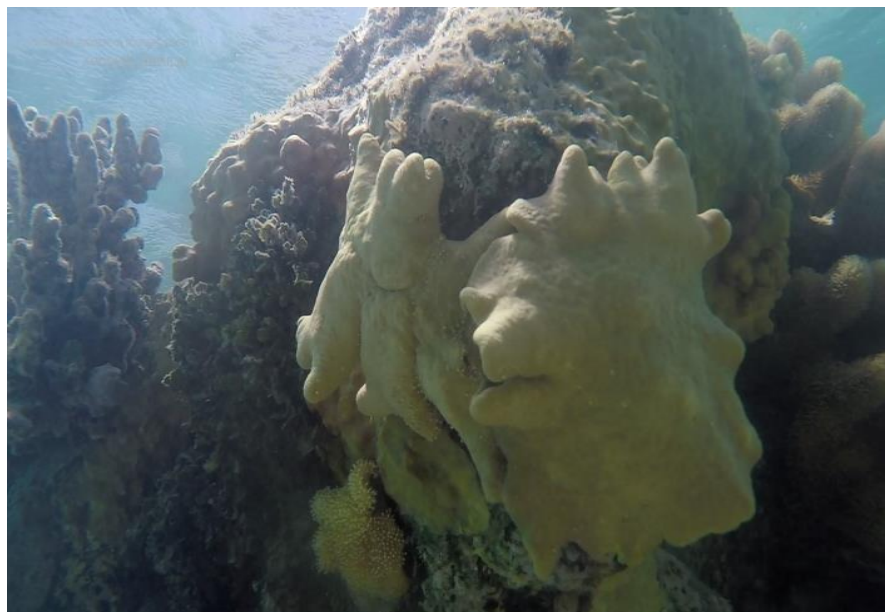

Figure1: Sarcophyton spongiosum photographed in its Red Sea habitat

\section{Results and discussion:}

Frozen bodies of $S$. spongiosum were chopped and extracted by methanol. The salts of the methanolic extract was removed by Diaion HP20 column. The desalted extract was subjected to a preliminary phytochemical screening. It was then fractionated by a vacuum liquid chromatography (VLC) column which eluted with the solvents $n$-hexane, DCM, EtOAc, and $\mathrm{MeOH}$ successively to afford the corresponding fractions. The antileishmanial and cytotoxic activities of the total desalted methanolic extract and the fractions obtained from it were assessed.

\subsection{Preliminary phytochemical screening}

The total desalted methanolic extract of S. spongiosum were subjected to a preliminary phytochemical screening for its chemical constituents following standard protocol [14]. The results (Table 1) revealed that the total desalted methanolic extract contains carbohydrates/glycosides, sterols, and diterpenes. The results also demonstrated the absence of anthraquinones, flavonoids, saponins, tannins, cardiac glycosides, alkaloids and coumarins. These results are matched with the preliminary chemical screening reported for other Sarcophyton species [15] and with the chemical reviews of the genus Sarcophyton [5, 16]. According to the results of the chemical screening and the reported cytotoxicity of steroidal compounds [13] and antileishmanial activity of diterpenes [17]; the cytotoxic and antileishmanial activity of the total desalted extract and its fractions were investigated.

Table 1: Results of the preliminary chemical screening of the total desalted methanolic extract of $S$. spongiosum

\begin{tabular}{ccc}
\hline NO & Test & Results \\
\hline 1 & Carbohydrates/ glycosides & + \\
2 & Flavonoids & - \\
3 & Sterols & + \\
4 & diterpenes & + \\
5 & Anthraquinones & - \\
6 & Saponins & - \\
7 & Tannins & - \\
8 & Alkaloids & - \\
9 & Cardiac glycosides & - \\
10 & Coumarins & - \\
\hline
\end{tabular}

\subsection{Cytotoxic activity}

The assay result (Table 2) demonstrated that the EtOAc fraction was the most promising cytotoxic against A549 and HepG2 cell lines $\left(\mathrm{IC}_{50} 13.4 \pm 1.2\right.$ and $11.6 \pm 19 \mu \mathrm{g} / \mathrm{mL}$, respectively) by comparing to the etoposide activity $\left(\mathrm{IC}_{50} 18.1 \pm 1.2\right.$ and $17.9 \pm$ $0.2 \mu \mathrm{g} / \mathrm{mL}$ respectively). The DCM fraction showed strong activity against $\mathrm{MCF}-7$ cell line $\left(\mathrm{IC}_{50} 31.5 \pm 1.1\right)$ as compared to the etoposide $(28.1 \pm 2.1 \mu \mathrm{g} / \mathrm{mL})$. The total methanolic extract and the $\mathrm{MeOH}$ fraction exhibited weak activities against the respected cell lines (Table 2). The $n$-Hexane fraction was inactive against all tested cell lines under the maximum concentration used $(100 \mu \mathrm{g} / \mathrm{mL})$. the strong activity of the EtOAc fraction may be attributed to its expected high contents of polyhydroxylated sterols which are reported to have strong cytotoxic activity [13]. This is the first report on evaluation of the cytotoxic activity of $S$. spongiosum.

\subsection{Antileishmanial activity}

As a part of our continuous efforts to find new treatments for cutaneous leishmaniasis from marine organisms [13], the anti- $L$. major activity of $S$. spongiosum total methanolic extract, different fractions were examined. The results (Table 2) revealed that the DCM fraction showed noticeable antileishmanial activity ( $\mathrm{IC}_{50} 28.1 \pm 1.2$ ) while the EtOAc fraction and the total methanolic extract exhibited moderate activity $(37.0 \pm 1.4$ and $42.2 \pm 2.4 \mu \mathrm{g} / \mathrm{mL}$, respectively) as compared with the standard antileishmanial miltefosine $\left(\mathrm{IC}_{50}\right.$ $8.1 \pm 1.9 \mu \mathrm{g} / \mathrm{mL})$. The $n$-Hexane and $\mathrm{MeOH}$ fractions were inactive under the maximum concentration used (Table 2). The antileishmanial activity of the DCM fraction may be attributed to the expected higher contents of its diterpenes in comparison with the other fractions. This is the first report on the antileishmanial activity of the soft coral S. spongiosum. Further phytochemical investigation is highly recommended to characterize metabolites of the active DCM fraction.

\section{Experimental}

\subsection{Material and methods}

\subsubsection{General Experimental Procedures}

The cancer cell lines used in these experiments were gained from the Japanese National Institute of Biomedical Innovation, Japan. The parasites L. major was obtained from the Institute of Tropical Medicine, Nagasaki University, Japan. The media used for biological assessment and their constituents as well as MTT and etoposide and miltefosine standards were obtained from Nacalai Tesque, Kyoto, Japan. The culture plates were purchased from Franklin Lakes, NJ, USA. The chemicals used in the preliminary phytochemical screening were purchased from El-Nasr Pharmaceutical and Chemical Co., Egypt (ADWIC). They include: Hager's reagent, $\alpha$-naphthol, concentrated sulfuric acid, Wagner's reagent, concentrated Hydrochloric acid, ammoniaium hydroxide, Dragendroff's reagent, acetic anhydride, copper acetate, $\mathrm{FeCl}_{3}$, Mayer's reagent, sodium picrate, and sodium hydroxide. 
Table 2: Cytotoxic and anti-leishmanial activities of the total desalted methanolic extract and fractions of the soft coral S. spongiosum.

\begin{tabular}{ccccc}
\hline Samples & & Cytotoxicity & Anti-leishmanial activity \\
& & A549 & HepG2 & MCF- major \\
IC50 $\mu \mathrm{g} / \mathrm{mL}($ mean \pm SE) & \\
\hline Total extract & $86.0 \pm 2.7$ & $89.6 \pm 4.5$ & $91.2 \pm 3.4$ & $>2.2 \pm 2.4$ \\
$n$-Hexane Fr & $>100$ & $>100$ & $>100$ & $28.1 \pm 1.2$ \\
DCM Fr & $19.9 \pm 1.6$ & $21.3 \pm 3.2$ & $31.5 \pm 1.1$ & $37.0 \pm 1.4$ \\
EtOAc Fr & $13.4 \pm 1.2$ & $11.6 \pm 1.9$ & $52.7 \pm 3.8$ & $>100$ \\
MeOH Fr & $71.8 \pm 2.8$ & $77.3 \pm 3.6$ & $86.2 \pm 5.4$ & - \\
Etoposide & $18.1 \pm 1.2$ & $17.9 \pm 0.2$ & $28.1 \pm 2.1$ & $8.1 \pm 1.9$ \\
Miltefosine & - & - & - &
\end{tabular}

\subsubsection{Animal materials}

The soft corals $S$. spongiosum were collected and identified by the co-author Dr. Abdallah Alian. The samples were collected from the Red Sea on the Egyptian coast, Hurghada province, in a depth of $(5-12 \mathrm{~m})$ in March 2018 via Contained Underwater Breathing Apparatus (SCUBA) techniques. A voucher specimen (SS-14) was deposited in Faculty of Pharmacy, Al-Azhar University.

\subsection{Extraction and isolation}

The fresh collected samples of $S$. spongiosum ( $750.0 \mathrm{gm}$ wet wt.) were chopped into small pieces and extracted exhaustively by maceration in methanol (3L each time). The solvent was distilled off to obtain a dry residue $(27.0 \mathrm{gm})$ which then subjected to desalting by Diaion HP20 column to afford the total methanolic extract $(20.0 \mathrm{gm})$ after removal of salts and pigments. The obtained extract $(20.0 \mathrm{gm})$ was fractionated by silica gel VLC column $(12 \times 5 \mathrm{~cm})$ and eluted successively with $n$-hexane (2L), DCM (2 L), EtOAc (2 L), and MeOH (2 L) affording the respective fractions $(1.0,4,7$ and $5 \mathrm{~g}$, respectively)

\subsection{Preliminary phytochemical screening}

The chemical constituents of the total desalted methanolic extract was screened according to the reported standard protocol [14], it can be summarized as following:

\subsubsection{Detection of carbohydrates}

Molisch's test: In a test tube, about 2 drops of alcoholic solution of $\alpha$-naphthol are added to one $\mathrm{mL}$ of aqueous solution of the extract. On the side of this test tube, around $2 \mathrm{~mL}$ of conc $\mathrm{H}_{2} \mathrm{SO}_{4}$ is added carefully. At the junction; a violet ring appears.

\subsubsection{Detection of flavonoids}

Ammonia test: on a filter paper, one drop of the aqueous solution of the extract is fumigated with ammonia. A yellow color appears.

\subsubsection{Detection of steroids}

In a dry test tube, about $5 \mathrm{mg}$ of the extract is dissolved in $4 \mathrm{~mL}$ of chloroform and divided into two test tubes $(2 \mathrm{~mL}$ each) to carry out the following tests;
Libermann-Burchard test: To one of the test tubes; a few drops of acetic anhydride and a few drops of conc. $\mathrm{H}_{2} \mathrm{SO}_{4}$ are added. The solution turns red, then blue and bluish green at the final. Salkowski test: To the other test tube, $2 \mathrm{ml}$ of conc. $\mathrm{H}_{2} \mathrm{SO}_{4}$ is added. The chloroform layer turns bluish red, cherry red, or purple in color.

\subsubsection{Detection of diterpenes}

Copper acetate test: A few drops of the copper acetate solution is added to the aqueous extracts. Emerald green color is formed.

\subsubsection{Detection of anthraquinones}

Borntrager's test: In a test tube; about $12 \mathrm{~mL}$ of benzene is added to the alcoholic extract, shaken well, and filtered. To the filtrated solution, about $6 \mathrm{~mL}$ of $10 \%$ ammonium hydroxide solution is added, shaken again and the test tube is left aside for a while. After the two layers were separated, the ammonia phase turns pink, to violet color.

\subsubsection{Detection of saponins}

Froth test: The dry extract or the dry powder is dissolved or suspended in distilled water, shaken vigorously for 5 minutes, and left aside for 10-15 min. A stable froth appears.

\subsubsection{Detection of tannins}

Braymer's test: About $2 \mathrm{~mL}$ of $10 \%$ alcoholic $\mathrm{FeCl}_{3}$ solution is added to the aqueous solution of the dry extract. The solutions turn blue-black or green color.

\subsubsection{Detection of alkaloids}

The crude extract is dissolved in $2 \mathrm{~N} \mathrm{HCl}$ and filtered. The filtrate is subjected to the following tests.

Dragendroff's test: one drop of the filtrate on a filter paper is sprayed with Dragendroff's reagent (solution of potassium bismuth iodide). a red precipitate is formed.

Mayer's test: one $\mathrm{mL}$ of the filtrate is added to few drops of Mayer's reagent (potassium mercuric iodide) in a test tube. A white precipitate is formed.

Wagner's test: one $\mathrm{mL}$ of the filtrate is added to few drops of Wagner's reagent (iodine in potassium iodide) in a test tube. A brown to reddish precipitate is formed

Hager's test: one $\mathrm{mL}$ of the filtrate is added to few drops of Hager's reagent (saturated picric acid solution) in a test tube. A yellow precipitate is formed. 


\subsubsection{Detection of cardiac glycoside}

Keller-Kiliani's test: A bout $1 \mathrm{~mL}$ of $\mathrm{FeCl}_{3}$ reagent (99 volume of glacial acetic acid and 1 volume of $5 \% \mathrm{FeCl} 3$ ) is added to the dry extract and shaken. Then, a few drops of conc. $\mathrm{H}_{2} \mathrm{SO}_{4}$ is added. The solution turns greenish blue in color within a few minutes due to the deoxy sugar part of the cardiac glycosides.

Baljet's test: about $1 \mathrm{~mL}$ of sodium picrate solution is added to equal volume of the aqueous extract. A yellow to orange color appears.

\subsubsection{Detection of coumarins}

Opened loop-closed loop response test: about $1 \mathrm{~mL}$ of ethanol extract is stirred in a test tube. 2 drops of $1 \% \mathrm{NaOH}$ solution is added and heated in water bath for 3-4 min to until the solution becomes clear. 4 drops of $2 \% \mathrm{HCl}$ is added to the clear solution. The solution turns cloudy.

\subsection{Cytotoxic assay}

The cytotoxic activity toward the three cancer cell lines (MCF7, A549, and HepG2) was carried out by MTT assay. In brief, the Dulbecco's modified Eagle's medium and a 96-well plate were used for the cancer cell's culture. Around $99 \mu \mathrm{L}$ of medium containing $5 \times 10^{3}$ cells and $1 \mu \mathrm{L}$ of the sample solution was added to each well. After that, the plate was incubated for three days. The incubator condition was [temperature; $37{ }^{\circ} \mathrm{C}$, atmosphere; $5 \% \mathrm{CO}_{2}$ ]. The media were aspirated at the end of the incubation period and $100 \mu \mathrm{L}$ of MTT solution was added and incubated again for an hour. The solution was aspirated and $100 \mu \mathrm{L}$ of DMSO was added to dissolve the formed formazan crystals. The absorbance was measured at $540 \mathrm{~nm}$ using a Molecular Devices Versamax tunable microplate. The standard cytotoxic agent (etoposide) was used as positive control and DMSO was the negative one. Each experiment was carried out in triplicate. The following equation was used to calculate the cytotoxic activity:

$\%$ inhibition $=\left[1-\left(\mathrm{A}_{\text {test }}-\mathrm{A}_{\text {blank }}\right) /\left(\mathrm{A}_{\text {control }}-\mathrm{A}_{\text {blank }}\right)\right] \times 100$ where $\mathrm{A}_{\text {control }}$ is the absorbance of the control (DMSO) well, $A_{\text {test }}$ the absorbance of the test wells, and $A_{\text {blank }}$ the absorbance of the cell-free wells [11, 13].

\subsection{Antileishmanial assay}

The L. major promastigotes growth inhibitory effect was carried out by the MTT assay as well. The logarithmic growth phase of the promastigotes was cultured by the same way as the cancer cell lines but under $25{ }^{\circ} \mathrm{C}$ and the number of cells was $\left(1 \times 10^{5}\right.$ cells/well). Also, after adding the MTT solution, the plate was incubated again for $12 \mathrm{hr}$ instead of $1 \mathrm{hr}$ in the cytotoxic assay. The same steps mentioned in the cytotoxicity were followed and the measurements were taken by the same way. The same equation was used for calculating the antileishmanial activity. The positive antileishmanial control was Miltefosine and DMSO was the negative one. Each experiment was carried out in triplicate as well $[11,13]$.

\section{Conclusion}

The total methanolic extract of S. spongiosum is rich in sterols and diterpenes. The DCM soluble-fraction showed strong cytotoxic activities against MCF-7 cell line and noticeable antiprotozoal activity against $L$. major. The EtOAc fraction exhibited potent cytotoxic activity against A549 and HepG2 cell lines. The S. spongiosum active fractions could be considered as a promising resource for the discovery of anti- $L$. major and cytotoxic agents and deserve more investigations.

\section{Acknowledgment}

The authors thank the Egyptian Ministry of Higher Education for the scholarship for the first author.

\section{Conflict of Interests}

The authors declare that there is no conflict of interest.

\section{References}

[1] Abou El-Ezz RF, Ahmed SA, Radwan MM, Ayoub NA, Afifi MS, Ross SA, Szymanski PT, Fahmy H, Khalifa SI. Bioactive cembranoids from the Red Sea soft coral Sarcophyton glaucum. Tetrahedron Letters. 2013;54(8):989-92.

[2] Dai CF. Interspecific competition in Taiwanese corals with special reference to interactions between alcyonaceans and scleractinians. Marine ecology progress series. Oldendorf. 1990;60(3):291-7.

[3] Pawlik JR. Marine invertebrate chemical defenses. Chemical Reviews. 1993; 93(5):1911-22.

[4] Zidan SA, Orabi MA, Mustafa MA, AAl-Hammady M, Kamel MS. AntiHSV-1 and hepatoprotective activities of the Soft coral Sarcophyton acutum from the red sea. Journal of Pharmacognosy and Phytochemistry. 2016;5(5):247-252.

[5] Liang LF, Guo YW. Terpenes from the soft corals of the genus Sarcophyton: Chemistry and biological activities. Chemistry \& biodiversity. 2013; 10(12):2161-96.

[6] Wilson CM, Tobin S, Young RC. The exploding worldwide cancer burden. International Journal of Gynecologic Cancer. 2004;14(1):121-132.

[7] Houghton P, Fang R, Techatanawat I, Steventon G, Hylands PJ, Lee CC. The sulphorhodamine (SRB) assay and other approaches to testing plant extracts and derived compounds for activities related to reputed anticancer activity. Methods. 2007; 42(4):377-87.

[8] Orabi MA, Taniguchi S, Sakagami H, Yoshimura M, Amakura Y, Hatano T. Hydrolyzable tannins of tamaricaceous plants, structures and cytotoxic properties of oligomeric ellagitannins from leaves of Tamarix nilotica and cultured tissues of tamarix tetrandra. Journal of Natural Products. 2016;79(4):984-95.

[9] Alvar J, Vélez ID, Bern C, Herrero M, Desjeux P, Cano J, Jannin J, den Boer M, WHO Leishmaniasis Control Team, Leishmaniasis worldwide and global estimates of its incidence. PloS one. 2012; 7(5): e35671.

[10] Orabi MA, Zidan SA, Attia GH, Alyami HS, Matsunami K, Hatano T. Ellagitannins and simple phenolics from the halophytic plant Tamarix nilotica. Natural Product Research. 2020:1-9.

[11] Asaumi S, Kawakami S, Sugimoto S, Matsunami K, Otsuka H, Shinzato T. Alkylated benzoquinones: ardisiaquinones A-H from the leaves of Ardisia quinquegona and their anti-leishmania activity. Chemical and Pharmaceutical Bulletin. 2018;66(7):757-63.

[12] Rodriguez F, John SF, Iniguez E, Montalvo S, Michael K, White L, Liang $\mathrm{D}$, Olaleye OA, Maldonado RA. In vitro and in vivo characterization of potent antileishmanial methionine aminopeptidase 1 inhibitors. Antimicrobial Agents and Chemotherapy. 2020;64(6): 213-221.

[13] Zidan SA, Abdelhamid RA, Al-Hammady M, Fouad MA, Matsunami K, Orabi MA. Cytotoxic polyhydroxy sterols from the Egyptian Red Sea soft coral Sarcophyton acutum. Fitoterapia. 2020;147: 104765.

[14] Morsy N. Phytochemical analysis of biologically active constituents of medicinal plants. Main Group Chemistry. 2014;13(1):7-21.

[15] Zidan SA. Chemical and biological investigations of Sarcophyton acutum Tixiur-Duravoult 1970 collected from Red Sea. Master thesis of Pharmacognosy, Minia University; 2016.

[16] Zubair MS, Al-Footy KO, Ayyad SE, Al-Lihaibi SS, Alarif WM. A review of steroids from Sarcophyton species. Natural Product Research. 2016;30(8):869-79.

[17] Fokialakis N, Kalpoutzakis E, Tekwani BL, Skaltsounis AL, Duke SO. Antileishmanial activity of natural diterpenes from Cistus sp. and semisynthetic derivatives thereof. Biological and Pharmaceutical Bulletin. 2006;29(8):1775-8. [18] Carvalho JF, Silva MM, Moreira JN, Simões S, Sá e Melo ML. Sterols as anticancer agents: synthesis of ring-B oxygenated steroids, cytotoxic profile, and comprehensive SAR analysis. Journal of Medicinal Chemistry. 2010;53(21):7632-8. 